\title{
Effect of the planned therapeutic communication program on therapeutic communication skills of pediatric nurses
}

\author{
Jaklein R. Younis ${ }^{* 1}$, Sohair M. Mabrouk ${ }^{1}$, Fawzia F. Kamal ${ }^{2}$ \\ ${ }^{1}$ Faculty of nursing, Menoufiya University, Menoufiya, Egypt \\ ${ }^{2}$ Faculty of nursing, Benha University, Benha, Egypt
}

Received: March 4, 2015

DOI: $10.5430 /$ jnep.v5n8p109
Accepted: May 11, 2015

Online Published: June 10, 2015

URL: http://dx.doi.org/10.5430/jnep.v5n8p109

\begin{abstract}
Background: Therapeutic communication is the basis of interactive relationships among health team and their patients: that affords opportunities to establish rapport, understand the client's experience, formulate individualized or client interventions and optimize health care resources. Aim: this study was carried out to assess the effect of a planned therapeutic communication program on therapeutic communication skills of pediatric nurses.

Methods: Setting: the study was carried out at Shebin El kom and Benha University hospitals. Research design: a quasi experimental research design was utilized. Sample: all staff nurses (132) who are working at the previously mentioned settings were included. Tools: Two tools were used for data collection. Tool one: a therapeutic communication questionnaire: consisting of two parts: (a) Socio-demographic structured questionnaire to obtain demographic data of the studied sample and (b) a structured therapeutic communication knowledge questionnaire to assess nurses' knowledge pre and post therapeutic communication program. Tool two is a five points Likert-scale structured check list used to assess the degree of improvement in pediatric nurses' skills and practice of therapeutic communication.

Results: The results of this study showed a positive statistical significant correlation between total knowledge score and total practice score of nurses' therapeutic communication skills at each measurement time (pre: $r=0.52, p<.00$; post $r=0.53, p<$ .001 ). Also, a highly statistical significant improvement in pediatric nurses' knowledge, practice and skills regarding therapeutic communication was found $p<.001$.

Conclusions: It was concluded that pediatric nurses had significant improvement in their knowledge and skills regarding therapeutic communication with their hospitalized child patients after utilization of a planned therapeutic communication program. Recommendation: Continuously implement advanced therapeutic communication programs for pediatric nurses to enhance safe and healthy interactions, foster trust and improve recovery of their hospitalized children.
\end{abstract}

Key Words: Therapeutic communication, Pediatric nurse, Skills

\section{INTRODUCTION}

The importance of communication and interaction for nursing has been an often stated point by nurses and nursing scientists since Florence Nightingale in the 19th century that continues today. Approaches and methods to enhance effec- tive nurse-patient interaction and communication vary. As professionals spend most of their time with pediatric patients, nurses ultimately hold a position of obvious importance in the health-care team to satisfy the communication needs of hospitalized children. ${ }^{[1,2]}$

*Correspondence: Jaklein R.Younis; Email: rjaklein@yahoo.com; Address: Faculty of nursing, Menoufiya University, Menoufiya, Egypt. 
Nurses have long understood the centrality of therapeutic relationships and the significance of effective nurse-client communication. Therapeutic communication is the basis of interactive relationships and affords opportunities to establish rapport, understand the client's experience, formulate individualized or client's-interventions and optimize health care resources. The current challenge in health care is to create an environment in which open and transparent communication is the norm rather than the exception. One way to do this is by adopting strategies that have been successful in health care settings as providing a standardized learning communication module to nurses. ${ }^{[3,4]}$ This will increase awareness of teaching communication in health care, and in the climate of greater emphasis on quality patient care. ${ }^{[5]}$ Studies have shown that $71 \%$ of malpractice techniques are the result of communication problems. It's a tremendous advantage for nurses to learn these skills, both for themselves and for their hospitalized children. ${ }^{[1,6]}$

Unfortunately, many health care workers are used to poor communication, as a result of a culture of low expectations that has developed in many health care settings. This culture, in which health care workers have come to expect faulty and incomplete exchange of information, leads to errors because even conscientious professionals tend to ignore potential red flags and clinical discrepancies. They view these warning signals as indicators of routine repetitions of poor communication rather than unusual worrisome indicators. ${ }^{[7,8]}$ Joint Commission International (JCI $)^{[9]}$ who works to improve patient safety and quality of health care by offering education, publications, advisory services, and international accreditation and certification in more than 100 countries, reported that, between 44,000 and 98,000 patients die every year in United States (U.S.) hospitals because of practice errors. More specifically, the Joint Commission cites communication failures as the leading root cause for medication errors, delays in treatment, and wrong-site surgeries, as well as the second most frequently cited root cause for operative and postoperative events and fatal falls. ${ }^{[10]}$

Therapeutic communication is the core of all elements of management. Additionally, it is a central part of nursing practice, it is important in delivery of effective and appropriate nursing care. It seems evident that current nursing philosophy assumes that communication and negotiation are pivotal concepts to the provision of high quality care. Therefore, it is essential for nurses to develop and maintain competent communication and interpersonal skills continuously that are required to facilitate therapeutic interactions, assess child needs, and implement interventions that promote an optimal level of functioning. ${ }^{[11]}$ Fostering an environment of trust and respect, accountability, situational awareness, open communication, assertiveness, shared decision-making, feedback, and education, via interdisciplinary training has brought significant improvements to communication flow in the health setting. It is important to consider that communication is not just verbal in form. One study states that $93 \%$ of communication is more affected by body language, attitude, and tone, leaving only $7 \%$ of the meaning and intent based on the actual words said. Whereas the spoken words contain the crucial content, their meaning can be influenced by the style of delivery, which includes the way speakers stand, speak, and look at a person. ${ }^{[12]}$

Nurses are expected to treat children, young people and their parents as individuals and respect their dignity. What is most important to children can only be obtained by communicating directly with children themselves rather than relying on parents. Consultations about children's care usually have three participants-nurse, parent and child. Children often take a passive role or are marginalized, sometimes by parents' interventions Nurses need to take account of children's views and preferences, and build alliances with parents and children. Nursing needs to develop its own evidence base for practice, to underpin training and education. ${ }^{[13]}$

Although poor communication can lead to tragic consequences, a review of the literature also shows that effective communication can lead to the following positive outcomes: improved information flow, more effective interventions, improved safety, enhanced employee morale, increased patient and family satisfaction, decreased lengths of stay and improved quality of children' ${ }^{[14]}$ Moreover, accurate communication is a two-way process. It is a give-and-take situation. On average, $70 \%-80 \%$ of our total working day is spent in some form of communication; moreover, $45 \%$ of that time is spent in listening. Listening effectively is one of the most powerful therapeutic communication tools that the nurse can have. ${ }^{[15]}$ Further, to achieve positive children health outcomes, health care professionals especially nurses and other stakeholders, must be able to communicate effectively with the populations they serve about disease prevention, treatment plans, risks and benefits, medication instructions, and other topics related to effective health care. National organizations have identified health care communication as an essential element of public health and a core component of the health care system. ${ }^{[16]}$

Although effective therapeutic communication with hospitalized children is increasingly understood as a key to effective child-centered care in all health care settings, the quantity and quality of training that nurses get in ways to promote and enhance effective nurse child communication is sadly lacking. A large body of literature indicates the critically 
important need for clinicians to have standardized communication tools to create a therapeutic environment in which individuals can speak up and express concerns. This literature concurs that when a team needs to communicate complex information in a short period of time, it is helpful to use structured therapeutic communication techniques to ensure accuracy of provided care. ${ }^{[17]}$ Also, research shows that in these disciplines, the adoption of standardized tools and behaviors is a very efficient strategy in enhancing effective therapeutic communication, alleviating difference in communication styles and reducing children's risks. ${ }^{[18]}$

The Joint Commission in the United States moves rapidly forward with new and revised requirements to improve child provider communication applicable to the hospitals' accreditation program. What is needed now is energetic action by health care decision-makers to move forward more quickly in adopting and adapting enhanced therapeutic communication skills. ${ }^{[19]}$ Therapeutic communication is central to nursing practice and can be particularly challenging in the care of children and their families. More researches concerning enhancement of therapeutic communication among nurses and hospitalized child patient are needed. Also, pediatric nurses need to continuously develop their own evidence based therapeutic communication practice based on advanced training and education. In addition, nurses should be well trained about signs of communication distress and the process of appropriate referrals to communication specialists, such as speech language pathologists and other needed children' care. ${ }^{[20]}$ For these crucial reasons, the present study aimed to assess the effect of a planned therapeutic communication program on therapeutic communication skills of pediatric nurses.

\subsection{Aim of the study}

The aim of the study was to assess the effect of a planned therapeutic communication program on therapeutic communication skills of pediatric nurses.

\subsection{Hypothesis}

Pediatric nurses who utilized a planned therapeutic communication program will experience better improvement in their therapeutic communication skills with their hospitalized children.

\section{Methods}

\subsection{Design}

Quasi-experimental research design.

\subsection{Setting}

The study was conducted at (Department of pediatrics, pediatric intensive care unit and pediatric dialysis unit) at the following two settings:

(1) Shebin El kom University Hospital and

(2) Benha University hospitals.

\subsection{Sample}

All staff nurses who were available at the time of data collection in the previously mentioned setting were included. They consisted of 132 staff nurses, 57 of them were working at Shebin El kom University Hospital, and the other 75 working at Benha University Hospital.

\subsection{Tools}

Two tools were developed by the researchers based on review of related literature. ${ }^{[11,21-24]}$

Tool one: Therapeutic communication structured questionnaire: it consisted of two parts: Part 1: Socio-demographic structured questionnaire: it includes hospital name, department, age, qualification, place of residence (rural or urban), years of experience (less than or greater than 3 years) and previous attendance of training courses regarding therapeutic communication skills. Part 2: Therapeutic communication knowledge questionnaire: It comprised eight questions administered to nurses to assess their knowledge regarding therapeutic communication skills. The score of the response answer were ranged from (1) correct answer and (2) incorrect answer.

Tool two: Likert scale structured performance checklist: to assess improvement in nurses' practice regarding therapeutic communication through observation. It consisted of 42 items that divided into 3 major headlines. Nurses' qualities concerning therapeutic communication skills consisted of 21 items, nurses' therapeutic communication skills during children' admission to hospital consisted of 4 items, and nurses' therapeutic communication skills while giving nursing care consisted of 17 items. The scoring system was based on a 5-point Likert scale performance checklist as follows; (5) Always, (4) mostly, (3) sometimes, (2) rarely and (1) never.

\subsubsection{Reliability of the tools}

Reliability was applied by the researcher for testing the internal consistency of the tool, by administration of the same tools to the same subjects under similar conditions on one or more occasions. Answers from repeated testing were compared (Test-re-test reliability).

\subsubsection{Validity of the tools}

The tools were tested for content validity by jury of five experts in the field of Pediatric nursing and nursing administration to ascertain relevance and completeness. 


\subsection{Data collection methods}

Data was collected at the first of September 2013 to the end of October 2014. An official letters were issued from the Faculty of Nursing Menoufia University, and send to the directors of all the selected hospitals with an explanation of the aim of the study to get their permission.

\subsection{Ethical consideration}

An oral consent was obtained from pediatric nurses to participate in the study. During the initial interview the purpose of the study was explained. The subjects were assured that all information would be confidential and their participation in the study was voluntary without any costs.

\subsection{Pilot study}

The pilot study was conducted with 20 pediatric nurses who were excluded from the total sample size.

\subsection{Procedure of data collection}

Primarily an orientation about the therapeutic communication program and its purpose was done for the subjects. Also, they were informed about the schedule time and place of training. The knowledge and practice pre-test were completed before the beginning of the training program. Staff nurses were divided into three groups equally according to their setting, structured sessions about therapeutic communication were implemented three time weekly with a total number of 12 sessions within one month in the two selected settings.

Staff nurses who participating in the study were given an evidence based therapeutic communication module containing basic information regarding utilization of therapeutic communication with pediatric patients at the. After completion of the therapeutic communication program the post-test knowledge questionnaire was completed. Also, the post-test performance checkist for each nurse was completed in 30 to 45 minute to ensure the degree of improvement in their therapeutic communication skills and practice. The average number of observed nurses was 5-6 nurses daily.

\subsection{Implementation of the program}

It divided into three phases (pre assessment phase, implementation phase and post assessment phase).

\subsubsection{Pre assessment phase}

A comfortable, private place inside the hospital was chosen for the interviewers. Orientation was done about the researcher's name, purpose, significance, content of the study. Subjects were asked to fill the pre-assessment therapeutic communication structured questionnaire. Also, the Likert scale structured performance checklist was used to assess nurses' performance regarding therapeutic communication through observation.

\subsubsection{Implementation phase}

This study hypothesized that pediatric nurses who utilized a planned therapeutic communication program will experience better improvement in their therapeutic communication skills with their hospitalized children. This was achieved through 12 specific sessions. The training program was utilized several teaching methods such as: brain storming, lectures, discussion, providing examples. Data show, videos, role play, pictures and evidence based booklets. At the end of each session summary, feedback and further clarification were done for the vague items.

\subsubsection{Post assessment phase}

The post assessment test was done using the same therapeutic communication structured questionnaire, and the Likertscale structured performance checklist to assess level of improvement of pediatric nurses regarding utilization of therapeutic communication with their child patients.

\subsection{Statistical analysis}

The data collected were tabulated \& analyzed by SPSS (Statistical Package for the social Science Software) statistical package version 20 on IBM compatible computer. Quantitative data were expressed as mean \& standard deviation $(\mathrm{X} \pm \mathrm{SD})$ and analyzed by applying student t-test for normally distributed variables. Qualitative data were expressed as number and percentage.

$P$-value at .05 was used to determine significance regarding:

- $P$-value $>.05$ to be statistically insignificant.

- $P$-value $\leq .05$ to be statistically significant.

- $P$-value $\leq .001$ to be high statistically significant.

\section{RESULTS}

Table 1 illustrates socio-demographic characteristics of the studied sample. As shown in this table, the highest percentage of the study subjects $(75.8 \%)$ had their age more than and equal to 30 years old, the mean age was $27.13 \pm 2.19$ years. Regarding nurses' qualifications, the highest percentage of the study subjects $(66.7 \%)$ had a nursing diploma. the majority of studied sample $(80.3 \%)$ had more than three years of experience. As regard to place of residence, more than half of the study subjects $(52.3 \%)$ were from rural areas. The highest percentage of the studied sample $(87.1 \%)$ did not attend any communication courses.

Table 2 demonstrates distribution of nurse's therapeutic communication knowledge by their pretest \& post test. As noticed from the table, there was a highly statistically significant difference among total knowledge scores of studied 
sample regarding their pre $\&$ post test where $p<.001$. Also, the results revealed that Mean $\pm \mathrm{SD}$ of total knowledge scores at post test $(6.11 \pm 1.50)$ were higher than Mean \pm $\mathrm{SD}$ at pre test $(3.09 \pm 0.94)$.

Table 3 presents distribution of socio-demographic characteristics of the studied sample by their post test' knowledge total score concerning therapeutic communication skills. As indicated from the table, the highest percentage of studied sample who had satisfactory knowledge (70.3\%) whose age was 30 years or less, had diploma of nursing $(61.4 \%)$, had more than three years of experience $(85.1 \%)$ and had no chance to attend communication courses ( $83.2 \%$ ) Moreover, there was a statistically significant difference among the studied sample regarding socio-demographic characteristics on Knowledge at post-test.

Table 4 illustrates distribution of nurses' practicing therapeutic communication skills by their pre $\&$ posttest. As indicated by comparing between mean \pm SD of the performance check list total score at pre and post test. There was noticeable improvement in nurses' performance regarding therapeutic communication in the post-test where Mean \pm SD (38.83 \pm $2.78)$ compared to Mean \pm SD at pre-test (10.21 \pm 5.94$)$. Additionally, The differences in scores among pre and post-test, were highly statistically significant where $p<.001$.

Table 5 demonstrates distribution of socio-demographic characteristics of nurses by their post test' of practicing therapeutic communication skills. As the table shows, Mean \pm SD of studied subjects $(38.68 \pm 2.55)$ whose age was more than 30 years had bachelor of nursing $(39.47 \pm 2.50)$ had more than three years of experience $(39.65 \pm 2.79)$ and had chance to attend communication courses $(39.11 \pm 2.39)$ is higher than others. Moreover, there was a highly statistically significant difference among the studied sample regarding socio-demographic characteristics on practicing assertive communication skills at post-test, except with attending communication courses the difference was statistically significant where $p<.05$.

Table 1. Distribution of Socio-demographic characteristics of the studied sample

\begin{tabular}{|c|c|c|}
\hline Socio-demographic characteristics & No. of Nurses $(n=132)$ & Percent (\%) \\
\hline \multicolumn{3}{|l|}{ Age (years): } \\
\hline$\leq 30$ years & 100 & 75.8 \\
\hline$>30$ years & 32 & 24.2 \\
\hline Mean $\pm \mathrm{SD}$ & $27.13 \pm 2.19$ & \\
\hline Range & $20.00-48.00$ & \\
\hline \multicolumn{3}{|l|}{ Hospital: } \\
\hline Shebein El-kom University hospital & 57 & 43.2 \\
\hline Benha University hospital & 75 & 56.8 \\
\hline \multicolumn{3}{|l|}{ Working unit at hospital : } \\
\hline General pediatric department & 85 & 64.4 \\
\hline PICU unit & 25 & 18.9 \\
\hline Renal dialysis unit & 22 & 16.7 \\
\hline \multicolumn{3}{|l|}{ Qualifications: } \\
\hline Bachelor of nursing & 19 & 14.4 \\
\hline Associated degree & 25 & 18.9 \\
\hline Diploma of nursing & 88 & 66.7 \\
\hline \multicolumn{3}{|l|}{ Place of residence: } \\
\hline Urban & 63 & 47.7 \\
\hline Rural & 69 & 52.3 \\
\hline \multicolumn{3}{|l|}{ Years of experience: } \\
\hline $1-3$ years & 26 & 19.7 \\
\hline$>3$ years & 106 & 80.3 \\
\hline \multicolumn{3}{|l|}{ Attending communication courses: } \\
\hline Yes & 17 & 12.9 \\
\hline No & 115 & 87.1 \\
\hline Total & 132 & 100 \\
\hline
\end{tabular}


Table 2. Distribution of Nurses' therapeutic communication knowledge by their Pretest \& post test

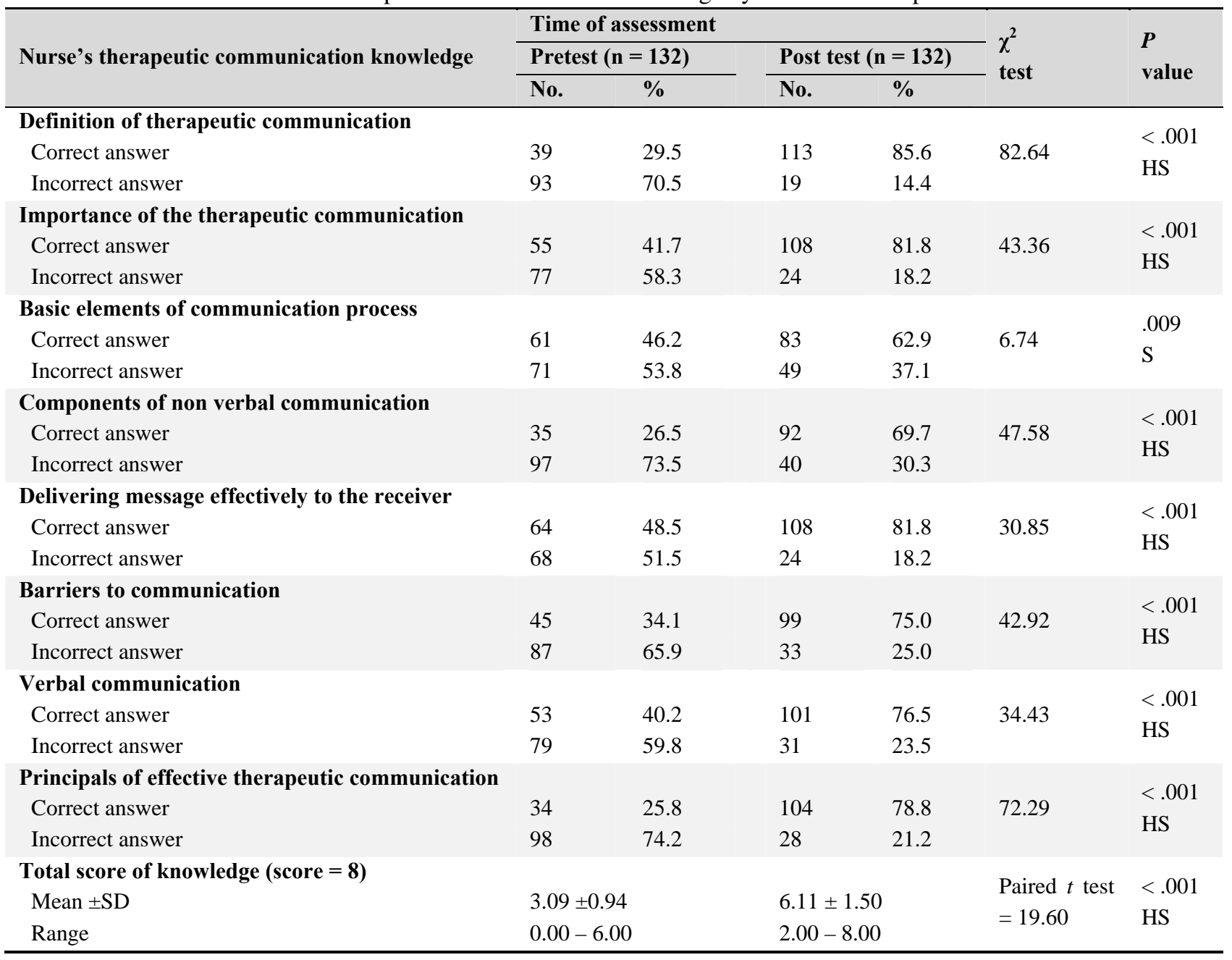

Note. HS: $P<.001$

Table 3. Distribution of Socio-demographic Characteristics of the studied sample by their post test' Knowledge total score regarding therapeutic communication

\begin{tabular}{|c|c|c|c|c|c|c|}
\hline \multirow{3}{*}{ Socio-Demographic characteristics } & \multicolumn{4}{|c|}{ Post test Knowledge $(n=132)$} & \multirow{3}{*}{$\begin{array}{l}\chi^{2} \\
\text { test }\end{array}$} & \multirow{3}{*}{$P$ value } \\
\hline & \multicolumn{2}{|c|}{$\begin{array}{l}\text { Satisfied } \\
(\text { Total score } \geq 60 \%)(n=101)\end{array}$} & \multicolumn{2}{|c|}{$\begin{array}{l}\text { Unsatisfied } \\
(\text { Total score }<60 \%)(n=31)\end{array}$} & & \\
\hline & No. & $\%$ & No. & $\%$ & & \\
\hline \multicolumn{7}{|l|}{ Age(years) } \\
\hline$\leq 30$ years & 71 & 70.3 & 29 & 93.5 & \multirow[t]{2}{*}{$5.77^{*}$} & \multirow[t]{2}{*}{$.02 *$} \\
\hline$>30$ years & 30 & 29.7 & 2 & 6.5 & & \\
\hline \multicolumn{5}{|l|}{ Qualifications } & \multirow{4}{*}{6.09} & \multirow{4}{*}{$.04 *$} \\
\hline Bachelor of nursing & 18 & 17.8 & 1 & 3.2 & & \\
\hline Technical institute of nursing & 21 & 20.8 & 4 & 12.9 & & \\
\hline Diploma of nursing & 62 & 61.4 & 26 & 83.9 & & \\
\hline \multicolumn{5}{|l|}{ Years of experience } & \multirow{3}{*}{5.15} & \multirow{3}{*}{$.02 *$} \\
\hline $1-3$ years & 15 & 14.9 & 11 & 35.5 & & \\
\hline$>3$ years & 86 & 85.1 & 20 & 64.5 & & \\
\hline \multicolumn{5}{|l|}{ Attending communication courses } & \multirow{3}{*}{$4.58 *$} & \multirow{3}{*}{$.03^{*}$} \\
\hline Yes & 17 & 16.8 & 0 & 0.0 & & \\
\hline No & 84 & 83.2 & 31 & 100 & & \\
\hline
\end{tabular}

*S: $P<.05$. 
Table 4. Distribution of Nurses' performance concerning therapeutic communication by their Pre \& Posttest

\begin{tabular}{|c|c|c|c|c|c|}
\hline \multirow{2}{*}{$\begin{array}{l}\text { Nurses' practicing assertive } \\
\text { communication skills }\end{array}$} & \multirow{2}{*}{$\begin{array}{l}\text { Maximum } \\
\text { score }\end{array}$} & \multicolumn{2}{|l|}{ Time of assessment } & \multirow{2}{*}{$\begin{array}{l}\text { Paired } t \\
\text { test }\end{array}$} & \multirow{2}{*}{$P$ value } \\
\hline & & Pre test $(n=132)$ & Post test $(n=132)$ & & \\
\hline \multicolumn{6}{|l|}{ Nurse's Qualities concerning } \\
\hline \multicolumn{6}{|c|}{ Therapeutic communication skills: } \\
\hline - Mean \pm SD & \multirow{2}{*}{21} & $6.70 \pm 2.06$ & $17.12 \pm 2.51$ & \multirow{2}{*}{36.87} & $<.001$ \\
\hline - Range & & $0.00-13.00$ & $12.00-21.00$ & & HS \\
\hline \multicolumn{6}{|c|}{ Therapeutic communication skills during } \\
\hline - Mean \pm SD & \multirow{2}{*}{4} & $1.46 \pm 0.25$ & $3.92 \pm 0.69$ & \multirow{2}{*}{38.51} & $<.001$ \\
\hline - Range & & $0.00-2.00$ & $3.00-4.00$ & & HS \\
\hline \multirow{2}{*}{\multicolumn{6}{|c|}{$\begin{array}{l}\text { Therapeutic communication skills during } \\
\text { nursing care: }\end{array}$}} \\
\hline & & & & & \\
\hline \multirow{2}{*}{$\begin{array}{l}\text { - Mean } \pm \text { SD } \\
\text { - Range }\end{array}$} & \multirow{2}{*}{17} & $7.88 \pm 2.09$ & $16.75 \pm 0.67$ & \multirow{2}{*}{46.43} & $<.001$ \\
\hline & & $0.00-10.00$ & $14.00-17.00$ & & HS \\
\hline \multirow{3}{*}{$\begin{array}{l}\text { Total score: } \\
\text { - Mean } \pm \text { SD } \\
\text { - Range }\end{array}$} & \multirow{3}{*}{42} & & & \multirow{3}{*}{$\mathrm{W}=50.14$} & \\
\hline & & $10.21 \pm 5.94$ & $38.83 \pm 2.78$ & & $<.001$ \\
\hline & & $0.00-33.00$ & $30.00-42.00$ & & HS \\
\hline
\end{tabular}

Note. HS: $P<.001$.

Table 5. Distribution of socio-demographic characteristics of pediatric nurses by their post test of practicing therapeutic communication skills

\begin{tabular}{|c|c|c|c|}
\hline Socio-Demographic characteristics & Post test (Mean \pm SD) & $t$-test & $P$ value \\
\hline $\begin{array}{l}\text { Age(years): } \\
\leq 30 \text { years } \\
>30 \text { years }\end{array}$ & $\begin{array}{l}34.88 \pm 2.16 \\
38.68 \pm 2.55\end{array}$ & 8.28 & $\begin{array}{l}<.001 \\
\mathrm{HS}\end{array}$ \\
\hline $\begin{array}{l}\text { Qualifications: } \\
\text { Bachelor of nursing } \\
\text { Technical institute of nursing } \\
\text { Diploma of nursing }\end{array}$ & $\begin{array}{l}39.47 \pm 2.50 \\
34.12 \pm 3.07 \\
31.89 \pm 2.74\end{array}$ & $F=59.41$ & $\begin{array}{l}<.001 \\
\mathrm{HS}\end{array}$ \\
\hline $\begin{array}{l}\text { Years of experience: } \\
1-3 \text { years } \\
>3 \text { years }\end{array}$ & $\begin{array}{l}37.68 \pm 2.62 \\
39.65 \pm 2.79\end{array}$ & 3.26 & $\begin{array}{l}<.001 \\
\mathrm{HS}\end{array}$ \\
\hline $\begin{array}{l}\text { Attending communication courses: } \\
\text { Yes } \\
\text { No }\end{array}$ & $\begin{array}{l}39.11 \pm 2.39 \\
36.79 \pm 2.84\end{array}$ & 3.20 & $\begin{array}{l}.002 \\
\mathrm{~S}\end{array}$ \\
\hline
\end{tabular}

Note. HS: $P<.001, F$ : Anova test

Figure 1 clarified a comparison between total knowledge score of nurses' therapeutic communication skills by their pre and post test. As noticed from this figure, there was a highly statistically significant difference among studied sample regarding total scores of knowledge by their pre \& post test where $p<.001$.

Figures 2 and 3 demonstrates correlation between total practice score of nurses' therapeutic communication skills and total knowledge score by their pre \& post test. The results indicated a positive correlation among studied subjects' total knowledge score and total practice score regarding therapeu- tic communication $(r=0.21, p<.01$ pre; $r=0.52, p<.001$ post ). This means that if the knowledge level of the studied subjects is high, the performance level is expected to be high.

\section{DiscuSsion}

Communication is an essential component of human experiences which involves the expression of emotions, ideas, and thoughts through verbal and nonverbal exchanges. It is the sense of social behavior and is the essential component to maintain a good interpersonal relationship. ${ }^{[25]}$ Therapeutic nurse-patient communication helps nurses to build positive 
relationships with patients by showing warmth, respect, and empathy. It also increases confidence of the nurse by enabling nurses to provide support, open up for feedbacks, and overcome anxiety. Therefore allows nurses to provide the best possible care for patients. ${ }^{[26]}$

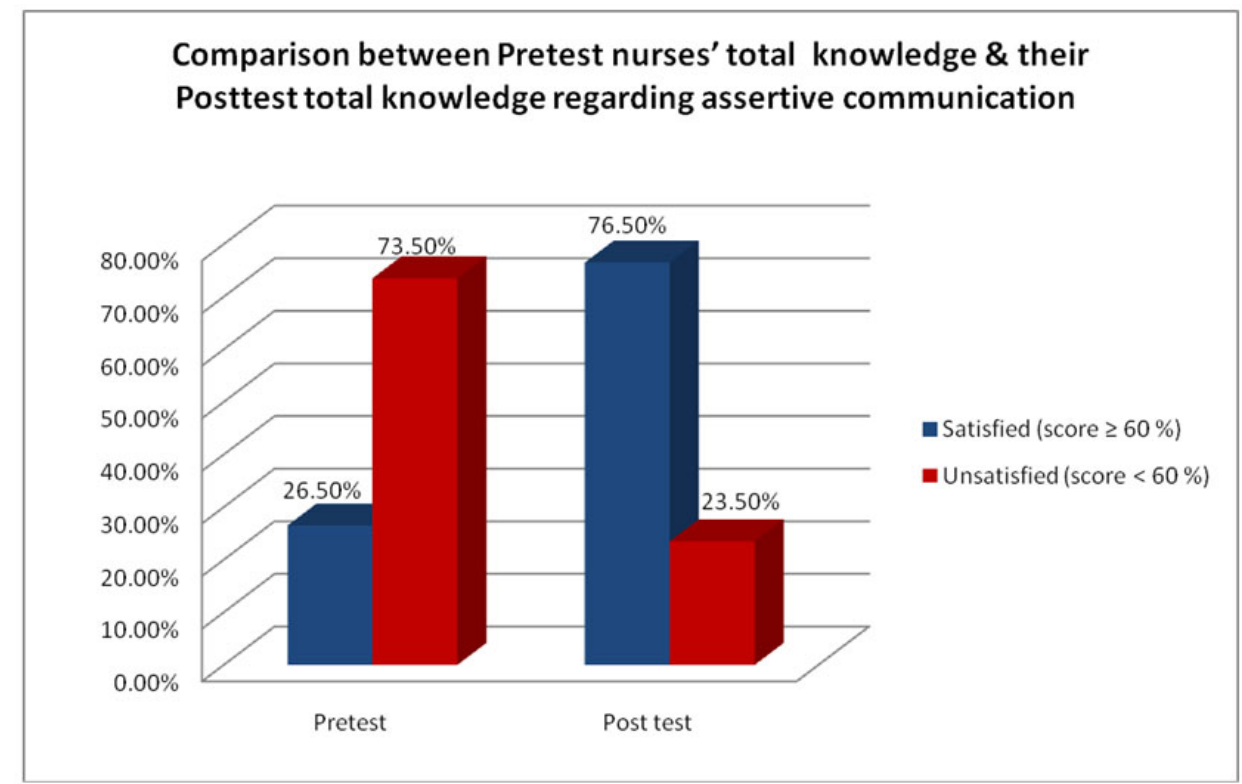

Figure 1. Comparison between total knowledge score of nurses' therapeutic communication skills by their pre and post test

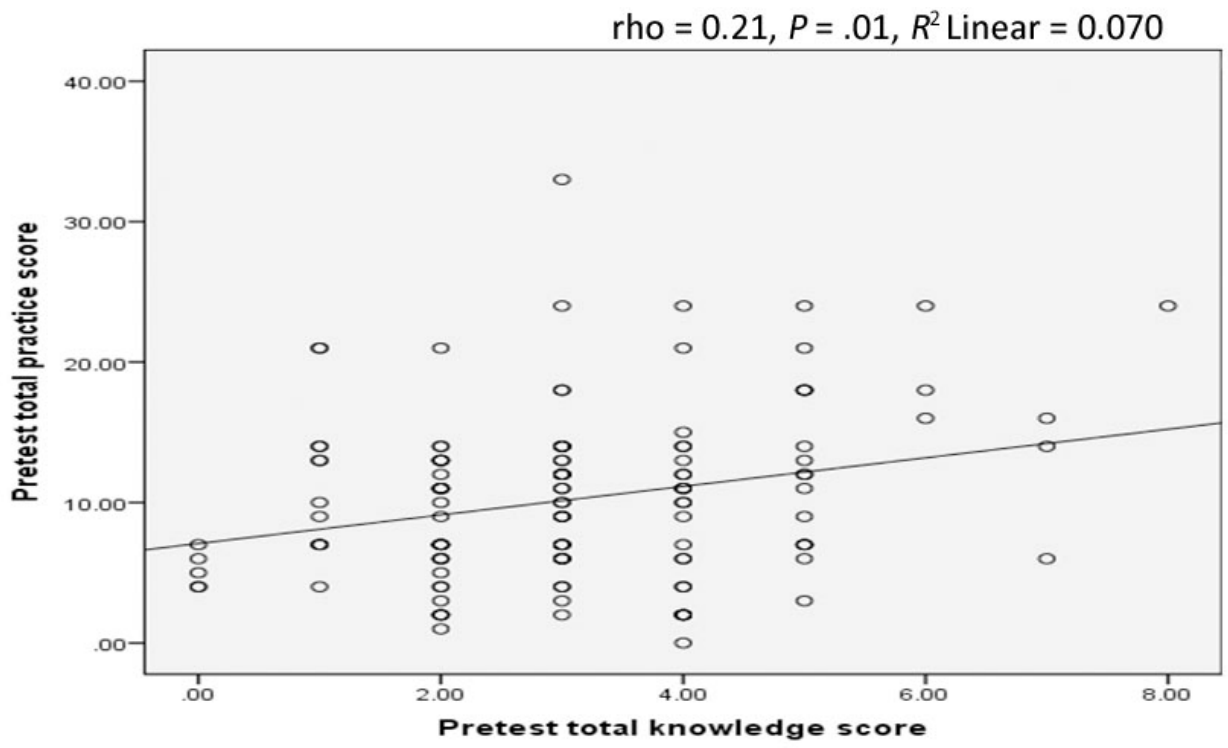

Figure 2. Correlation between total practice score of nurses' therapeutic communication skills and total knowledge score by their pretes test $(n=132)$

Although effective therapeutic communication with patients is increasingly understood as a key to effective, patientcentered care in all health care settings, the quantity and quality of training that nurses get in ways to promote and enhance effective nurse: patient communication is sadly lacking. ${ }^{[4]}$ So, it is recommended that communication skills training programs should be frequently used to develop these skills. $^{[27,28]}$

The present study aims to assess the effect of a planned therapeutic communication program on therapeutic communication skills of pediatric nurses. The result of the present study covered four main areas as follows; firstly; socio-demographic characteristic of the studied subjects; 
secondly, nurses' therapeutic communication knowledge, highest percentage of the studied sample didn't attend any thirdly, nurses' therapeutic communication skills and lastly, communication courses. The result comes in agreement with correlation between total practice score and total knowledge score of pediatric nurses regarding therapeutic communication skills.

In relation to attending communication courses of the studied sample the finding of the present study revealed that the

Prasad $^{[29]}$ who conducted a study to assess effectiveness of structured teaching module on therapeutic communication among staff nurses. They reported that the minority of nurses had an exposure to in-service education related to therapeutic communication.

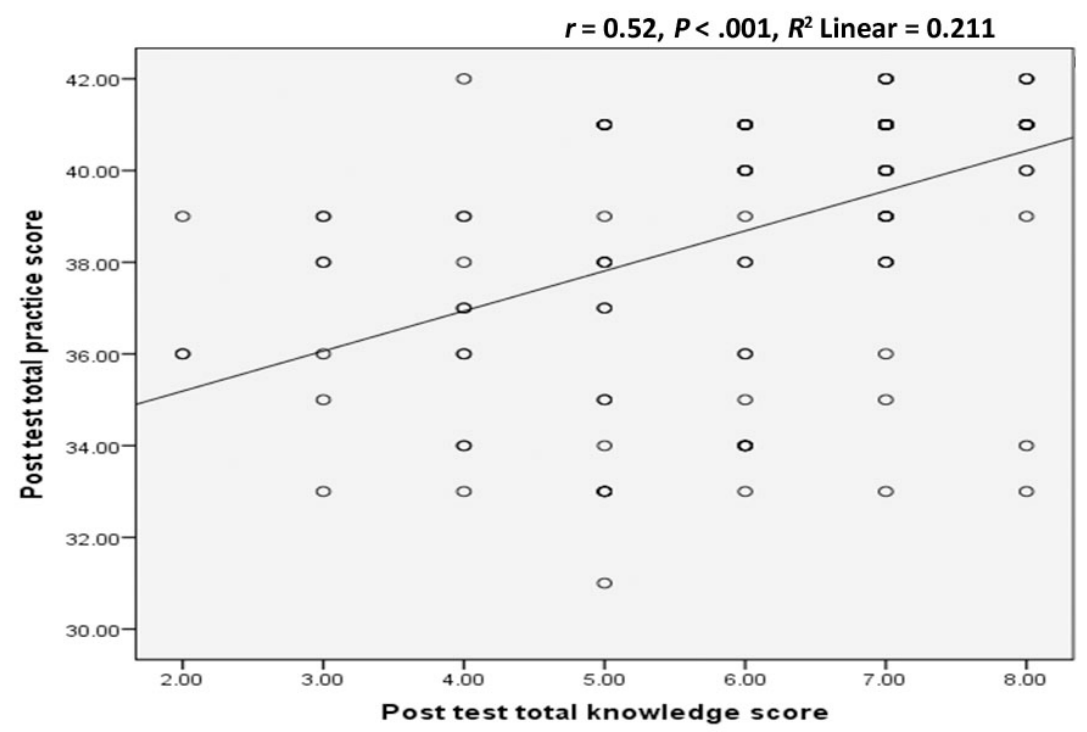

Figure 3. Correlation between total practice score of nurses' therapeutic communication skills and total knowledge score by their post test $(n=132)$

Regarding distribution of nurses' therapeutic communication knowledge by their Pretest $\&$ post test the finding of present study showed that, there was a highly statistically significant difference among studied sample regarding total scores of knowledge at pre \& post test. Also, the results revealed that total mean score of knowledge at post measurement time was higher than total mean score of knowledge at pre time. The result supported with Prasad et al. ${ }^{[29]}$ who showed in the pretest that, the majority of the staff nurses had poor knowledge about therapeutic communication. The post-test indicated that, (42\%) had acquired good knowledge and (58\%) of them were gained average knowledge. There was a statistical significant improvement in post-test knowledge scores of staff nurses.

In the same line, Rachel ${ }^{[30]}$ conduct a study to improve communication skills among nursing students. He demonstrated that study subjects become more confident about their communication knowledge and skills through the modeling also the study subject had sufficient to excellent cognitive understanding of the communication skills taught in the lesson. Consequently, the result of the present study is expected because exposure to a well designed communication skills program allows nurses to raise self-awareness and develop better knowledge and skills.

In relation to distribution of socio-demographic characteristics of the studied sample by their pretest' knowledge total score of therapeutic communication skills the finding of present study revealed that, the majority of the studied sample who had unsatisfactory knowledge aged 30 years or less, had diploma of nursing, had more than three years of experience and had no chance to attend communication courses. Moreover, there was a highly statistically significant difference between the studied subjects' socio-demographic characteristics regarding their pre-test knowledge. These results are consistent with Langewitz et al. ${ }^{[31]}$ who conducted a study to determine the effectiveness of a communication training program for oncology nurses. They showed that in the pre-test three quarters of the studied nurses had inadequate knowledge and skills regarding therapeutic communication.

As regard to distribution of socio-demographic characteristics of the studied sample by their posttest' therapeutic communication knowledge the result of the present study showed that the highest percentage of studied sample who had satisfactory knowledge aged 30 years or less, had diploma of 
nursing, had more than three years of experience and had no chance to attend communication courses. Further, there was a highly statistically significant difference between the studied subjects' socio-demographic characteristics regarding their post-test knowledge. The finding of this result comes in agreement with Prasad ${ }^{[29]}$ who stated that the pre-test knowledge score on therapeutic communication were independent of all selected demographic variables such as age, gender, educational status, experience and exposure to in-service education program. Also, this study is supported by Shattel ${ }^{[25]}$ who conducted a study to determine the effectiveness of a communication skill training program among clinicians; he showed that the pre-test knowledge score on communication was independent of selected demographic variables like age, education, occupation. Further, this result consistent with Abd-El-Moniem ${ }^{[32]}$ who conducted a study about impact of training program on the performance of nurses, he found that there was a positive correlation between knowledge and nurses age in follow-up test.

In relation to distribution of nurses' practicing therapeutic communication skills by their Pre \& Posttest the finding of the present study indicated that, nurses' information on practicing assertive communication skills improved in the post-test than pre-test. Additionally, there were highly statistically significant difference between pre and post-test. This study was supported by Gysels ${ }^{[33]}$ who conducted a study to determine the effectiveness of in-service communication training program on enhancement the empathic skills of nurses. They stated that the post test practice scores of nurses increased and nurses' empathic skills improved after utilization of communication training program.

This result is also consistent with McGilton ${ }^{[34]}$ who conducted a study about communication enhancement: nurse and patient satisfaction outcomes and Parry ${ }^{[35]}$ who also, conducted a study about enhance communication performance in allied health professionals. They suggest that training in communication lead to skill acquisition and improved patient outcomes. Also the result matched Jun ${ }^{[36]}$ who conducted a study about the development and evaluation of a communication skills training program for registered nurses in cancer care. He reported that the developed communication skills training program is effective in improving nurses' communication skills in cancer care. In congruence with the previous studies, the current result explained that, the well designed communication skills training program could be valuable and effective in improving pediatric nurses' communication skills, reinforcing basic communication practice, assisting in the acquisition of new communication skills, and ensuring best communication supply that ensure satisfied care.
Regarding distribution of Socio-demographic characteristics of pediatric nurses by their pre test of practicing assertive communication skills the present study showed that, the mean score of studied subjects who aged 30 years or less, had associated degree, had one to three years of experience and had no chance to attend communication courses was lower than others. Moreover, there was a highly statistical significant difference among the studied sample regarding socio-demographic characteristics on practicing assertive communication skills by their pre test. This result supported by $\mathrm{Viji}^{[24]}$ who conduct study about effectiveness of structured teaching module on therapeutic communication among staff nurses. They reported that pre-test knowledge score on therapeutic communication were independent of all selected demographic variables such as age, gender, educational status, experience and exposure to in-service education program. This result is agreement with Humphris ${ }^{[37]}$ who conduct study about nurses' communication skills knowledge \& understanding. He reported that, nurses' practicing communication skills "on the job" is not sufficient to fully master the necessary communication requirements for the patients.

In relation to distribution of socio-demographic characteristics of pediatric nurses by their post test of practicing assertive communication skills. The finding demonstrated that the mean score of studied subjects who aged more than 30 years, had bachelor of nursing, had more than three years of experience and had chance to attend communication courses was higher than others. Moreover, there was highly statistical significant difference among the studied sample regarding socio-demographic characteristics on practicing assertive communication skills at post-test. This result consistent with Dantoni ${ }^{[38]}$ who conduct study about training programs can improve nurse communication with patients about care goals, he noted that, nurses' communication abilities had improved after each session and they were motivated to enhancing these skills. Also, they felt more prepared to discuss goals of care and deliver it.

Regarding to correlation between total practice score of nurses' therapeutic communication skills and total knowledge score by their pre - post test. The finding revealed that, there was positive statistical significant correlation regarding total knowledge score and total practice score of pediatric nurses' assertive communication skills at each measurement time.

This finding agrees with Taha ${ }^{[39]}$ who conducted a study about impact of A designed teaching protocol on nurse's knowledge and practices, he documented positive correlation between age, knowledge and practice. Also the result agree 
with Mahdy ${ }^{[40]}$ conduct study about training program on staff nurses performance and empowerment toward care of patient undergoing organs and tissues transplantation, He founded that, there was a positive correlation between knowledge and practice. Based on the previous researches the current result of the present study means that, if the level of the study subjects' knowledge is high, the level of their skills is expected to be high at pre and post test

\section{Conclusion}

It was concluded that, pediatric nurses had significant improvement in their knowledge and skills regarding thera- peutic Communication with their hospitalized children after utilization of a planned therapeutic communication program.

\section{Recommendation}

The study recommended to continuously implementing advanced therapeutic communication programs for pediatric nurse to enhance safe and healthy interaction, foster trust and improve recovery of their hospitalized children.

\section{CONFLICTS OF INTEREST Disclosure}

The authors declare that there is no conflict of interest statement.

\section{REFERENCES}

[1] Lambert V, Glacken M. Communication between children and health professionals in a child hospital setting: a Child Transitional Communication Model: Journal Advanced Nursing. 2011; 67(3): 569-82. PMid:21091913 http://dx.doi.org/10.1111/j.136 5-2648.2010.05511.x

[2] Baron R. Barriers to Effective Communication: Implications for the Cockpit. 2014. Available from: http://www . iflyamerica.org/ barriers_to_effective_communications

[3] Craven RF, Hirnle CJ. Fundamentals of nursing human health and function. 5th ed. Lippincott; NewYork: 2007; 235-251.

[4] Chapman A, Kimberly B. Improving Communication among Nurses, Patients, and Physicians. American Journal of Nursing. 2009; 109(11): 21-25. PMid:19826329 http://dx.doi.org/10.1097 /01.NAJ.0000362013.53342.17

[5] Chen A, Mutha S, Rodriquez M, et al. Addressing Language and Culture: A Practice Assessment for Health Care Professionals. California Academy of Family Physicians Foundation. 2007; 1-36.

[6] Edwards C. Communication Skills Training for Elementary School Students, at Western Michigan University, Kalamazoo, MI, USA. Communication Currents, a publication of the National Communication Association. 2009.

[7] Lisa KS. Communication for Nurses: Talking with Patients:2 nd , Jones \& Bartlett, Canada; 2009; 204.

[8] Patak L, Happ B. Improving Patient-Provider Communication: A Call to Action. Journal of Nursing Administration. 2009; 39(9): 372376. PMid:19745632 http://dx. doi .org/10.1097/NNA . 0 b013 e3181b414ca

[9] Joint Commission International. The Pathway to JCI Accreditation for Hospitals: a proven pathway to accreditation. 2004. Available from: http://www. joint commissioninternational.org/

[10] Fallow L, Jenkins V, Farewell V, et al. Enduring impact of communication skills training: results of a 12-month follow-up. British Journal of Cancer. 2003; 89(8): 145-149.

[11] Shafer E. Doctor-patient communication critical to patient care, expectations often not met. Hem Onc Today. 2007; Available from: http: //www . hemonctoday $\cdot$ com/article . aspx?rid=23725

[12] Barrere L, Cynthia C. Discourse Analysis of Nurse-Patient Communication in a Hospital Setting: Implications for Staff Development. Journal for Nurses in Staff Development. 2007; 23(3): 114122. PMid:17538264 http://dx.doi.org/10.1097/01 . NND. 00 $00277180.47829 .8 \mathrm{~d}$

Published by Sciedu Press
[13] Ramos E. Communicating with Patients who have Speech/Language Difficulties: Guidance for Medical \& Nursing Staff. Communication Matters. 2008.

[14] McCarthy B, Twomey A. Person-centered communication: Design, implementation and evaluation of a communication skills module for undergraduate nursing students - an Irish context. Contemporary Nurse. 2008; 27(2): 207. PMid:18457521 http://dx.doi.org/1 0.5172 /conu.2008.27.2.207

[15] Happ B. Communicating with mechanically ventilated patients: State of the Science. AACN Clinical Issues: Advanced Practice in Acute and Critical Care. 2001; 12(2): 247-258. PMid:11759552 http://dx.doi.org/10.1097/00044067-200105000-00008

[16] Heaven C, McCarron M. Transfer of communication skills training from workshop to workplace: the impact of clinical supervision. Patient Education Counseling. 2006; 60(3): 313-25. PMid:16242900 http://dx.doi.org/10.1016/j.pec.2005.08.008

[17] Finke HL, Kitko L. A systematic review of the effectiveness of nurse communication with patients with complex communication needs, with a focus on the use of augmentative and alternative communication. Journal of Clinical Nursing. 2008; 17(16): 2102-2115. PMid: 18705734 http://dx.doi .org/10.1111/j.1 365-2702.2008.02373.x

[18] Bronwyn V, Parmenter T. Nursing the patient with severe communication impairment. Journal of Advanced Nursing. 2011; 35(6): 827-835. http://dx.doi.org/10.1111/j.1365-2648. 1988.tb01435. $x$

[19] Paxton R, Rhodes D, Crooks I. Teaching nurses therapeutic conversation: a pilot study. Journal of Advanced Nursing. 2008; 13(3): 401-404.

[20] Joint Commission on Accreditation of Healthcare Organizations (JCAHO, 2005). The Joint Commission guide to improving staff communication. Oakbrook Terrace, IL: Joint Commission Resources.

[21] Berg L, Skott C, Danielson E. Caring relationship in a context: fieldwork in a medical ward. International Journal Nursing Practice. 2007; 3: 100-106. PMid:17394517 http://dx.doi .org/10.1111/j.1 440-172X.2007.00611.x

[22] Wolf L, Lukas H. Swiss Cancer League communication skills training program for oncology nurses: an evaluation. Journal of advanced nursing. 2010; 66(7): 1421.

[23] Zavertnik JE, Huff TA, Munro CL. Innovative approach to teaching communication skills to nursing. Journal of Nursing Education. 2010; 49(2): 65-71. PMid:19810670 http://dx.doi.org/10.3928/0 1484834-20090918-06 
[24] Viji P, Samuel G. Effectiveness of structured teaching module on therapeutic communication among staff nurses. Journal of Nursing and Health Science. 2014; 2(3): 27-31.

[25] Shattel S. Issues in clinical nursing, nurse- patient interaction. 2003.

[26] Shurst A, Taylor S. Communication, communication, communication. Nursing \& Residential Care. 2010; 12(3): 140-142. http: //dx.doi.org/10.12968/nrec. 2010.12.3.46685

[27] Mullan BA, Kothe EJ. Evaluating a nursing communication skills training course: The relationships between self-rated ability, satisfaction, and actual performance. Nurse Education Practice. 2010; 10(6): 374-378. PMid:20541974 http://dx.doi.org/10.1016/j.nep r.2010.05.007

[28] Radtke JV, Tate JA, Happ MB. Nurses' perceptions of communication training in the ICU. Intensive Critical Care Nurses. 2012; 28(1): 16-25. PMid:22172745 http://dx.doi.org/10.1016/j.iccn. 2011.11 .005

[29] Prasad V, George S. Effectiveness of Structured Teaching Module on Therapeutic Communication among staff nurses. Journal of Nursing and Health Science. 2014; 3(2): 7-31.

[30] Rachel S. Improving communication skills among nursing students: assessing the comfort curriculum as an intervention. Master Theses. University of Kentucky. 2012.

[31] Langewitz W, Heydrich L. Swiss Cancer League communication skills training program for oncology nurses: an evaluation. Journal of advanced nursing. 2010; 66(7): 1421.

[32] Abd-El-Moniem HA. Impact of training program on the performance of nurses working in intensive care units in Zagazig university hospitals. Doctorate Thesis, Faculty of Nursing, Zagazig University. 2001; 42-69.

[33] Gysels M, Richardson A. Effectiveness of communication training for health professionals. 2005.
[34] McGilton K, Robinson HI, Boscart V. Communication enhancement: nurse and patient satisfaction outcomes in a complex continuing care facility. Journal of Advanced Nursing. 2006; 54(1): 35. PMid:16553689 http://dx.doi.org/10.1111/j.1365-2 $648.2006 .03787 . \mathrm{x}$

[35] Parry R. Are interventions to enhance communication performance in allied health professionals effective, and how should they be delivered? Direct and indirect evidence. Patient Education and Counseling. 2008; 73(2): 186-195. PMid:18768287 http://dx.doi.org/10. $1016 / j$.pec. 2008.05 .029

[36] Jun L. The development and evaluation of a communication skills training program for registered nurses in cancer care in Beijing, China. 2005. Available from: http://repository.lib.polyu.e $\mathrm{du} . \mathrm{hk} / \mathrm{jspui} / \mathrm{handle} / 10397 / 1053$

[37] Humphris GM. Communication skills knowledge, understanding and OSCE performance in medical trainees: a multivariate prospective study using structural equation modeling. Medical Education. 2002; 36(9): 842e852.

[38] Dantoni T. Training programs can improve nurse communication with patients about care goals. ONS annual congress. 2012. Available from: http: //www. oncologynurseadvisor.com/08/

[39] Taha A. Emergency Nursing Care for Critically Ill Patients: Impact of A Designed Teaching Protocol on Nurse's Knowledge and Practices At Intensive Care Units (ICUS) of Benha University and Benha Teaching Hospitals, Master Thesis, Faculty of Nursing Benha University; 2006.

[40] Mahdy AY. Effect of training program on staff nurses performance and empowerment toward care of patient undergoing organs and tissues transplantation. Doctorate thesis, Fundamental of Nursing, faculty of nursing, Benha University; 2009; 114. 